\title{
An atypical presentation of sporadic ovarian Burkitt's lymphoma: case report and review of the literature
}

\author{
Paola Bianchi ${ }^{1}$, Francesco Torcia ${ }^{1}$, Marta Vitali ${ }^{1}$, Giuliana Cozza ${ }^{1}$, Marco Matteoli ${ }^{2}$ and Valentina Giovanale ${ }^{\text {* }}$
}

\begin{abstract}
Primary non-Hodgkin's lymphoma of the ovary is a rare occurrence. An ovarian involvement by non-Hodgkin lymphoma (NHL) may include one of the four subtypes of lymphoma: diffuse large B-cell lymphoma, Burkitt's lymphoma (BL), lymphoblastic lymphoma or anaplastic large cell lymphoma. Burkitt's lymphoma is a rare entity with a specific poorly differentiated pattern.

Most women experience an ovarian BL with abdominal pelvic pain, abnormal vaginal bleeding, bowel obstruction, urinary frequency, incontinence and abdominal mass. Sometimes these warning signs may be absent, causing a late and more difficult diagnosis.

Here we report a case of a primary ovarian Burkitt's lymphoma with bilateral involvement in a 57 year old patient. She firstly presented neurological symptoms in the upper limbs and she was treated with surgery and combined chemotherapy. The diagnosis of malignant lymphoma was established after bilateral adnexectomy and histological study of the excised tissue.
\end{abstract}

Keywords: Burkitt, Ovarian lymphoma, Hypoaesthesia, Oophorectomy, Chemotherapy

\section{Case report}

A 57-year-old pluriparous woman from Pakistan was admitted to the emergency ward due to a rapidly progressive weakness in her arms, bilateral hypoaesthesia of the 1st, 2nd and 3rd finger and wide-spread pain in her arms, shoulders and neck. Her medical history shows a $\mathrm{TBC}$ infection at the age of 17 . MRI revealed volumetric increase of right $\mathrm{C} 5-\mathrm{C} 6-\mathrm{C} 7$ and left $\mathrm{C} 6-\mathrm{C} 7$ nerve roots with a mild contrast enhancement as idiopathic neuritis. Rachicentesis was negative. Serological HIV, HBV, HCV, neurotropic virus tests and autoantibodies were negative. The hematologic findings showed a low lymphocyte count and a slight increase in neutrophils.

A Computer Tomography (CT) scan revealed multiple enlarged lymph nodes involving the bilateral supraclavicular, left laterocervical, left and right paratracheal, prevascular, aortopulmonary, left and right hilar and subcarinal groups (Figure 1).

\footnotetext{
* Correspondence: valentinagiovanale@libero.it

'Department of Gynecology-Obstetrics and Urological Sciences, "Sapienza"

University of Rome, S. Andrea Hospital, Rome, Italy

Full list of author information is available at the end of the article
}

In the pelvic cavity there was a solid inhomogeneous mass, with necrotic areas (Figure 2).

The patient was transferred to the gynaecological ward for a suspected adnexal neoplasia.

Further investigation showed high tumour markers with CEA level of 3,3 ng/ml and Ca 19.9 level of $81,2 \mathrm{UI} / \mathrm{ml}$; Ca $125, \alpha$-fetoprotein and $\beta$-HCG were negative. Serum immunofixation was negative for monoclonal components.

Vaginal ultrasound confirmed the presence of a left ovarian mass; it measured $88 \mathrm{~mm}$. There was no free fluid in the abdominal cavity.

A bone marrow biopsy and aspiration were performed, molecular evaluation showed a polyclonal rearrangement of the IgH gene.

The patient underwent a laparotomic bilateral annessiectomy; operative time length and mean haemoglobin drop value results were $60 \mathrm{~min}$ and $125 \mathrm{ml}$ respectively. No adhesions of tumors and other organs, no intraoperative and post-operative complications were observed. Cytological examination of the peritoneal washing was negative for neoplastic cells.

\section{() Biomed Central}

(c) 2013 Bianchi et al.; licensee BioMed Central Ltd. This is an Open Access article distributed under the terms of the Creative Commons Attribution License (http://creativecommons.org/licenses/by/2.0), which permits unrestricted use, distribution, and reproduction in any medium, provided the original work is properly cited. 


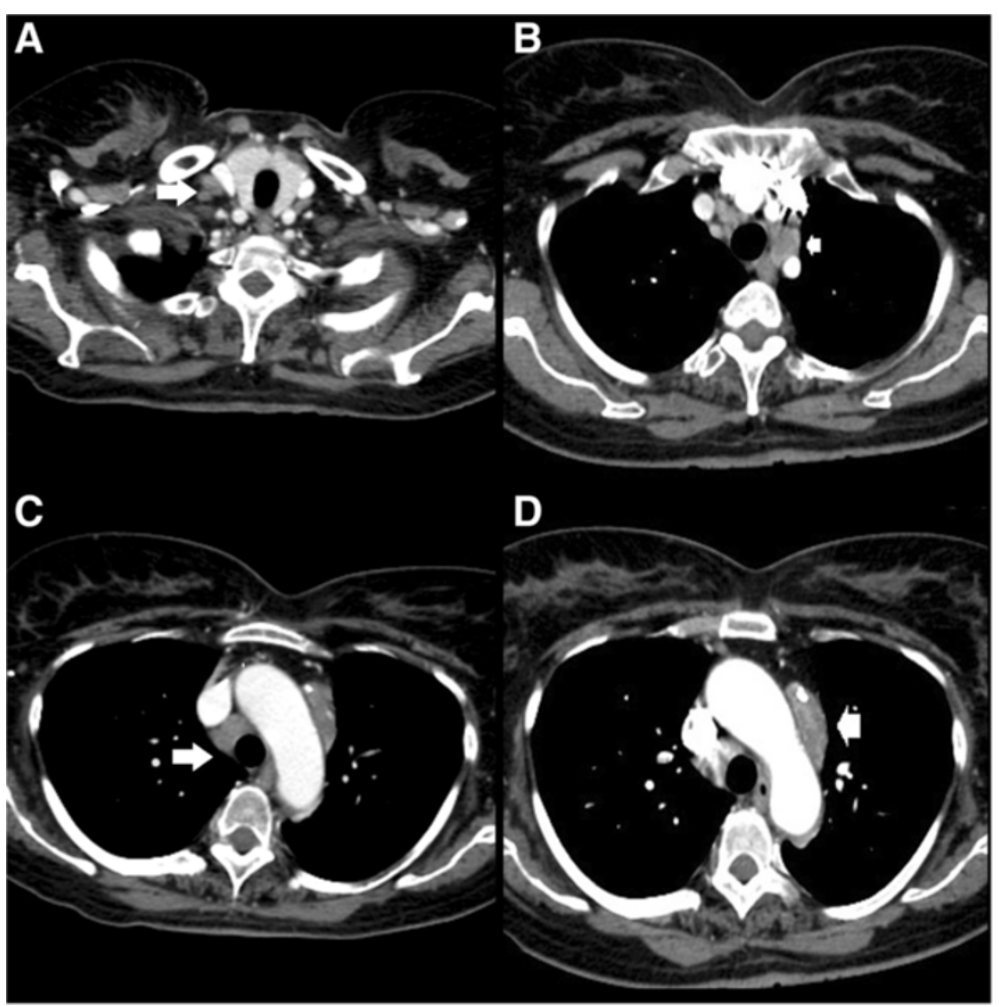

Figure 1 CT scan of mediastinum-axial section. CT scan of mediastinum shows diffuse lymphatic swelling (arrow) over right supraclavicular (A), pre-vascular (B-D) and aortopulmonary (C) station with inhomogeneous enhancing after contrast media, suggestive for lymphoma.

A histopathological examination revealed a high grade B-cell ovarian lymphoma.

Immunohistochemical evaluation revealed the presence of tumour cells that were positive for B-cell markers with a high proliferation rate (CD20, CD10 and CD79a) (Figure 3 and 4).

The FISH test was negative for c-myc t $(8 ; 14)$ translocation and PCR was negative for $\mathrm{t}(14 ; 18)$ translocation. These patterns indicated a not translocated Burkitt's lymphoma.
According to Ann Arbor Staging a diagnosis of stage IV A was confirmed. After surgical resection the patient was treated with an intensive G-mall chemotherapy protocol. In older patient (> 55 years) G-m all protocol contemplates a pre-phase of 5 days (cyclophosphamide $200 \mathrm{mg} / \mathrm{m}^{2}$ iv and prednisone $60 \mathrm{mg} / \mathrm{m}^{2}$ ), cycle $A^{1}$ from day 7 , cycle $A^{2}$ from day 49 and a cycle $\mathrm{A}^{3}$ from day 98 (rituximab $375 \mathrm{mg} / \mathrm{m}^{2}$ iv, dexamethasone $10 \mathrm{mg} / \mathrm{m}^{2}$ po , methotrexate $500 \mathrm{mg} / \mathrm{m}^{2}$ iv and $12 \mathrm{mg}$ i.th., ifosfamide $400 \mathrm{mg} / \mathrm{m}^{2}$ iv, cytarabine $2 \times 60$ $\mathrm{mg} / \mathrm{m}^{2}$ iv, VP16 $60 \mathrm{mg} / \mathrm{m}^{2}$ iv), cycle $\mathrm{B}^{1}$ from day 28 , cycle

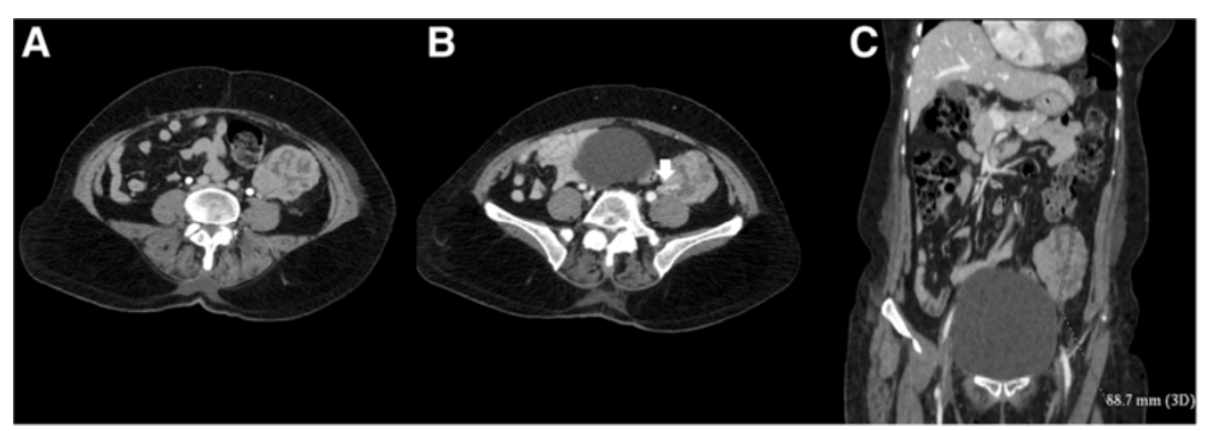

Figure 2 Pelvic CT scan-axial and coronal sections. CT scan of pelvis in arterial (A) and portal (B-C) phase, shows an inhomogeneous neoformation $65 \times 51 \times 88 \mathrm{~mm}$ in correspondence of left ovary, with multiple necrotic areas within and a slow-enhancing after contrastum media administration. Figure $2 \mathrm{~B}$ shows a vascular pedicle (white arrow) in the inferior portion of the lesion rising from left ovarian artery. 


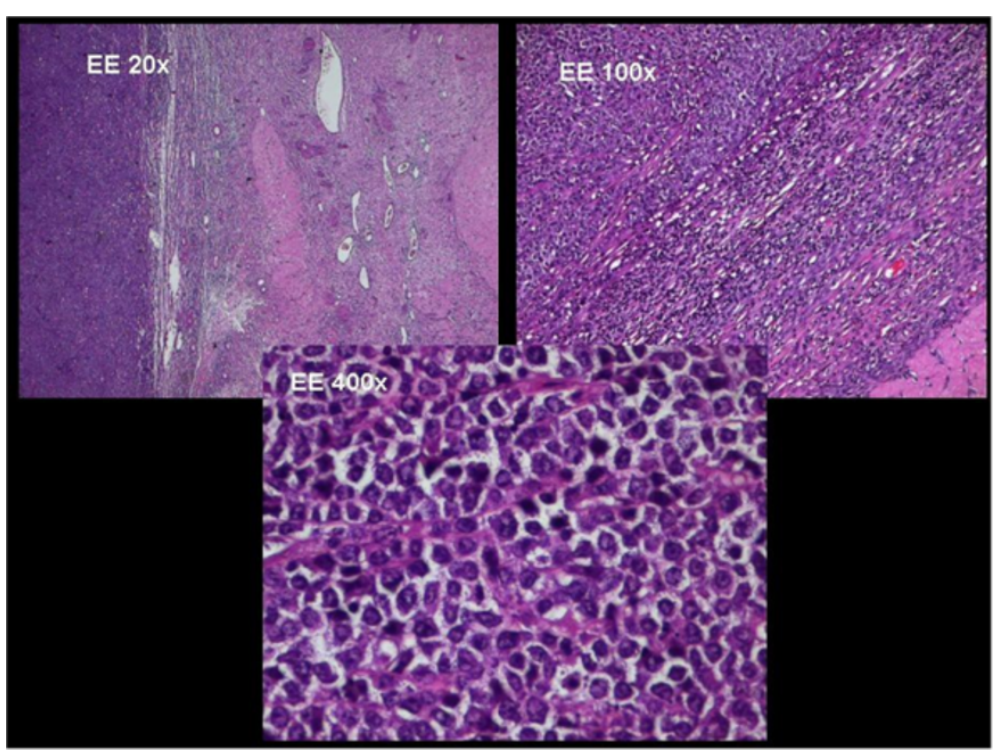

Figure 3 Histological examination of ovarian lymphoma. Hematoxylin and eosin-stained sections (original magnifications X20, X100 and X400) show a lymphoid proliferation of small B-cells with a widely monotonous growth pattern, suggestive for high-grade B-cell lymphoma. The round nuclei have finely clumped and dispersed chromatin with multiple basophilic medium size nucleoli, often located in paracentral side.

$\mathrm{B}^{2}$ from day 77 and cycle $\mathrm{B}^{3}$ from day 119 (rituximab $375 \mathrm{mg} / \mathrm{m}^{2}$ iv, dexamethasone $10 \mathrm{mg} / \mathrm{m}^{2}$ po, vincristine $1 \mathrm{mg}$ iv, methotrexate $500 \mathrm{mg} / \mathrm{m}^{2}$ iv and $12 \mathrm{mg}$ i.th., ciclofosfamide $200 \mathrm{mg} / \mathrm{m}^{2}$ iv, adriamicina $25 \mathrm{mg} / \mathrm{m}^{2} \mathrm{iv}$ ).

Post-operatively and post-CHT CT scan showed a volumetric reduction of the enlarged lymph nodes. Nevertheless the patient decided to sign her discharge papers, despite her poor physical condition and against the advice of her doctors.

\section{Discussion}

Burkitt's lymphoma (BL) is a highly aggressive, mature B-cell lymphoma that shows an extremely rapid growth rate [1,2]. In 2008, the World Health Organization

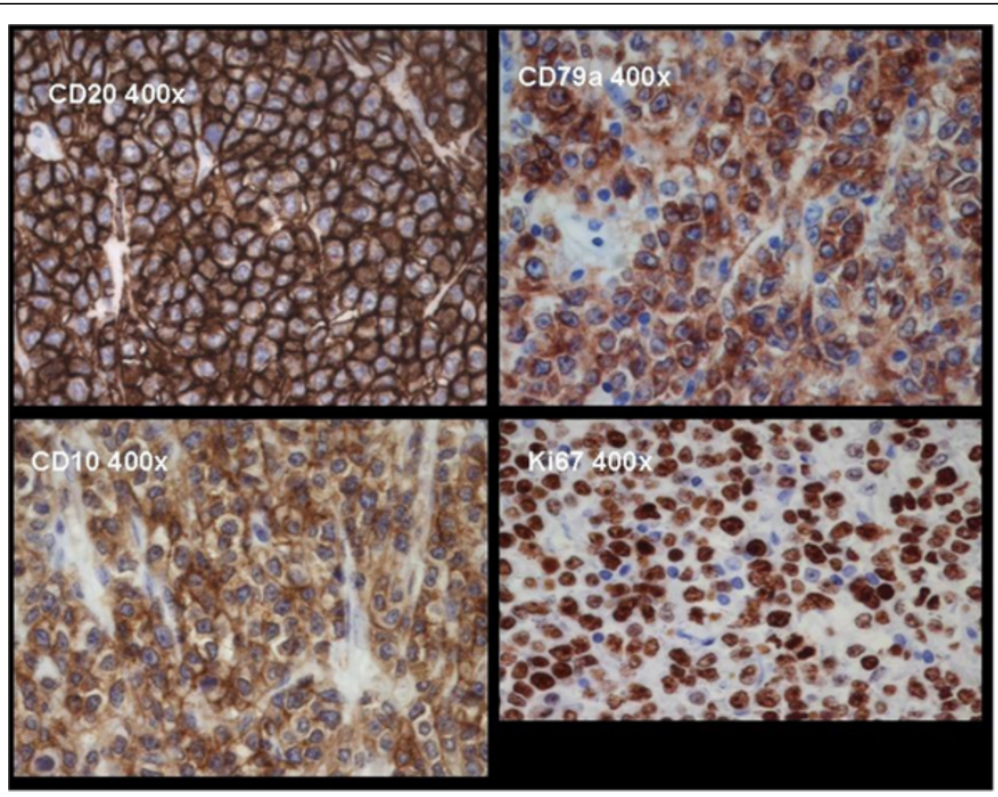

Figure 4 Immunohistochemical pattern. The slides show neoplastic B-cell CD20, CD79a (B cell associated antigen) and CD10 positive. The mitotic index of the lymphoma is very high with a Ki67 that is approssimately equal to 100. 
(WHO) classification recognizes three clinical subtypes of BL: African or endemic, sporadic and immunodeficiency associated. Burkitt's lymphoma of the ovaries can be primary or more frequently secondary to a systemic neoplastic process [3]. The ovary is often a site of secondary lymphomatous diffusion but less than $10 \%$ of ovarian lymphomas have their onset in the ovary [2]. The secondary involvement may be an initial clinical presentation of occult extra-ovarian disease or a manifestation of widely disseminated disease [4].

Primary ovarian lymphoma (POL) is an event that accounts for $0.5 \%$ of NHL and $1.5 \%$ of all ovarian neoplasia, usually bilateral and often associated with ascites [4-6].

In 1976, POL was defined by Fox and Langley with the following criteria [6]:

(a) the disease has to be confined to the ovary,

(b) absence of disease in the blood and bone marrow,

(c) the extraovarian deposits, if any, should appear at least after few months.

The most frequent clinical symptoms of gynaecologic $\mathrm{BL}$ are pelvic pain, abnormal vaginal bleeding, bowel obstruction and abdominal mass with a rapid growth; sometimes it shows unspecified symptoms with a more difficult differential diagnosis [7]. Burkitt's lymphoma is generally defined as a neoplasia with a typical, but not pathognomonic aspect of starry-sky pattern induced by mitotes of macrophages, with neoplastic cells that tend to form pseudoacini, structured in cords and nests. In our case the clinical presentation of lymphoma did not appear with the classical symptoms (fever, night sweats and weight loss) since the patient referred to the hospital manifesting the occurrence of hypoaestesia and weakness of both the upper limbs. After a MRI evaluation that identified a neurological compression of the cervical nerve roots by multiple lymphoadenopathy, a CT scan was performed and showed an adnexal mass. After surgical removal the histological, molecular and cytogenetic features indicated a not translocated Burkitt's lymphoma. According to the WHO classification up to $10 \%$ of $\mathrm{BL}$ cases may lack a MYC translocation, nevertheless MYC has a not specific involvement in BL [8].

Medical studies suggest that the origin of lymphomas in the ovaries is associated with the presence of preexisting lymphoid tissue in the ovary. Nevertheless other authors reveal that reactive lymphocytes may secondarily involve the ovary in response to inflammation (PID, endometriosis) or autoimmune diseases and then they may undergo malignant change and give rise to POL $[5,6]$. The medical literature suggests that Burkitt's lymphoma has to be considered in an adult woman with an ovarian mass, excluding granulose tumours, granulocytic sarcoma, poorly differentiated carcinoma, metastasis and epithelial ovarian neoplasia [3]. Being aware of the clinical impact of this potentially curable lymphoma, our case showed the importance of a detailed evaluation and multidisciplinary collaboration.

The prognosis of our patient, according to the International Prognostic Index of non-Hodgkin's lymphoma, is a 5-year survival of $43 \%$, corresponding to an highintermediate risk [9]. The International Prognostic Index (IPI) is a clinical tool used to predict the prognosis of patients with aggressive non-Hodgkin's lymphoma. For the evaluation of the prognosis this clinical score considers Ann Arbor staging, age, elevated serum lactate dehydrogenase (LDH), performance status, and number of extranodal sites of disease.

Written informed consent was obtained from the patient for publication of this Case report and any accompanying images. A copy of the written consent is available for review by the Editor-in-Chief of this journal.

The patient of our case gave her consent concerning the case report.

\section{Competing interests}

The authors disclose any commercial interest, any financial interest and any potential conflict of interest of other nature. No financial support has been required for this study.

\section{Authors' contributions}

PB has conceived and designed the study, has been performed the surgical intervention and has given final approval of the version to be published; FT and GC have supervised the work and were involved in acquisition of data; MM has made CT scan images processing in final form for publication; VG and MV have followed the patient during hospitalization and have drafted the manuscript. All authors have read and approved the final manuscript.

\section{Author details}

"Department of Gynecology-Obstetrics and Urological Sciences, "Sapienza" University of Rome, S. Andrea Hospital, Rome, Italy. ${ }^{2}$ Department of Radiology "Sapienza", University of Rome, S. Andrea Hospital, Rome, Italy.

Received: 29 April 2013 Accepted: 18 June 2013

Published: 4 July 2013

\section{References}

1. Blum KA, Lozanski G, Byrd JC: Adult Burkitt leukemia and lymphoma. Blood 2004, 104(10):3009-3020.

2. Vang R, Jeffrey Medeiros L, Warnke RA, Higgins JP, Deavers MT: Ovarian Non-Hodgkin's lymphoma: A clinicopathologic study of eight primary cases. Mod Pathol 2001, 14(11):1093-1099.

3. Gutiérrez-Garcì L, Medina Ramos N, Garcìa Rodriguez R, Barber MA, Arias MD, Garcìa JA: Bilateral ovarian Burkitt's lymphoma. Eur J Gynaec Oncol 2009, 30(2):231-233.

4. Crasta JA, Vallikad E: Ovarian lymphoma. Indian J Med Paediatr Oncol 2009 30(1):28-30.

5. Crawshaw J, Sohaib SA, Wotherspoon A, Sheperd JH: Primary non-Hodgkin's lymphoma of the ovaries: imaging findings. Br J Radiol 2007, 80:155-158.

6. Chishima F, Hayakawa S, Ohta Y, Sugita K, Yamazaki T, Sugitani M, Yamamoto T: Ovarian Burkitt's lymphoma diagnosed by a combination of clinical features, morphology, immunophenotype, and molecular findings and successfully managed with surgery and chemotherapy. J Gynecol Cancer 2006, 16(1):337-343. 
7. Dimopoulos MA, Daliani D, Pugh W, Gershenson D, Cabanillas F, Sarris AH: Primary ovarian non-Hodgkin's lymphoma: outcome after treatment with combination chemotherapy. Gynecol Oncol 1997, 64:446-450.

8. Swerdlow SH, Campo E, Harris NL, Jaffe ES, Pileri SA, Stein H, Thiele J, Vardiman JW: WHO classification of tumors of haematopoietic and lymphoid tissues, fourth edition. IARC WHO Classification of Tumours; 2007:264.

9. Lopez M: Oncologia medica pratica. 2nd edition. SEU; 2005:1913.

doi:10.1186/1757-2215-6-46

Cite this article as: Bianchi et al:: An atypical presentation of sporadic ovarian Burkitt's lymphoma: case report and review of the literature. Journal of Ovarian Research 2013 6:46.

\section{Submit your next manuscript to BioMed Central and take full advantage of:}

- Convenient online submission

- Thorough peer review

- No space constraints or color figure charges

- Immediate publication on acceptance

- Inclusion in PubMed, CAS, Scopus and Google Scholar

- Research which is freely available for redistribution 